\title{
Systemic Lupus Erythematosus Nephritis Class IV
}

National Cancer Institute

\section{Source}

National Cancer Institute. Systemic Lupus Erythematosus Nephritis Class IV. NCI

Thesaurus. Code C123118.

Systemic lupus erythematosus nephritis, with active or inactive diffuse, segmental or global endo- or extracapillary glomerulonephritis involving greater than or equal to 50\% of all glomeruli, typically with diffuse subendothelial immune deposits, with or without mesangial alterations. (Weening, Jan J. et al. (2004). The Classification of Glomerulonephritis in Systemic Lupus Erythematosus Revisited. Journal of the American Society of Nephrology 15(2), 241-50.) 